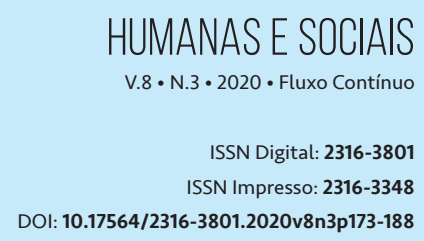

\section{RELAÇÕES INTERNACIONAIS E O EUROCENTRISMO: A CRÍTICA DO PENSAMENTO DECOLONIAL E O BEM VIVER COMO ALTERNATIVA}

INTERNATIONAL RELATIONS AND EUROCENTRISM:

THE DECOLONIAL THINKING CRITIIISM AND

THE GOOD LIVING ${ }^{1}$ AS AN ALTERNATIVE

RELACIONES INTERNACIONALES Y EL EUROCENTRISMO:

LA CRÍTICA DEL PENSAMIENTO DECOLONIAL

Y EL BUEN VIVIR COMO ALTERNATIVA

\section{RESUMO}

Este artigo tem como objetivo propor um breve debate entre a crítica pós-colonial no âmbito das Relações Internacionais e as vertentes de concepções surgidas na América Latina - o pensamento decolonial e os entendimentos do Bem Viver -, em busca de chamar atenção a outras possiblidades de informar o campo, que não apenas a preponderância em fatos e concepções surgidas do eurocentrismo. Em primeiro momento, faz-se uma abordagem breve sobre o pós-colonialismo nas Relações Internacionais, tratando-se de apontar as críticas ao caráter eurocêntrico da área. Adiante, segue-se com a análise do pensamento decolonial latino-americano, a fim de discutir como esses teóricos apresentam a crítica no pensamento social, em maior escopo. A discussão se encerra com a apresentação das ideias do Bem Viver, conceito baseado, essencialmente, nas concepções dos povos andinos e amazônicos. Busca-se demonstrar como, por meios que se iniciam no processo de colonização da América, a história que informa o campo das Relações Internacionais é centrada na visão europeia-ocidental, ocultando partes relevantes do passado e, com isso, outras visões de mundo, motivos pelos quais se encerra a discussão com a abordagem do Bem Viver como alternativa.

\section{PALAVRAS-CHAVE}

Relações Internacionais. Pós-colonialismo. Pensamento Decolonial. Eurocentrismo. Bem Viver.

1 A opção pelo uso da tradução "Good Living" se deu a partir da observância da forma de uso dos autores da área que serão aqui referenciados. 


\section{ABSTRACT}

The main purpose of this paper is to promote a brief debate among the postcolonial criticism in the International Relations' field and the strands of understanding emerged from Latin America, the decolonial thinking and the Good Living, in order to call the attention to other possibilities of informing the IR, not only that preponderance in facts and conceptions originated from the Eurocentrism. First of all, we make a short debate about the postcolonial thought in International Relations, bringing focus to the Eurocentric character of the area. Going forth, we follow with the analysis on the Latin American decolonial thinking, in order to discuss how its theorists elaborate their critics in the social thought, in a larger scale. The discussion is closed with the exposition about the ideas of the Good Living, concept which is based, essentially, on the conceptions of Andean an Amazonian peoples. With all this, we intend to demonstrate how, through means that have started in the America's colonization, the history that informs the discipline is centered on the European vision, keeping hidden relevant historical parts and, consequently, other worldviews, reasons by which we finish the discussion with the approach of the Good Living as an alternative.

\section{KEYWORDS}

International Relations. Postcolonialism. Decolonial thinking. Eurocentrismo. Goog Living.

\section{RESUMEN}

Este artículo tiene como objetivo proponer un breve debate entre la crítica poscolonial en el ámbito de las Relaciones Internacionales y las vertientes de concepciones surgidas en América Latina - el pensamiento decolonial y los entendimientos del Buen Vivir -, buscando llamar la atención a otras posibilidades de informar al campo, que no apenas la preponderancia en hechos y concepciones surgidas del eurocentrismo. En primer momento, se hace un abordaje breve sobre el poscolonialismo en Relaciones Internacionales, tratando de apuntarse las críticas al carácter eurocéntrico del área. Adelante, se sigue con el análisis del pensamiento decolonial latinoamericano, a fin de discutir como sus teóricos presentan la crítica en el pensamiento social, en mayor esfera. La discusión es finalizada con la presentación de las ideas del Buen Vivir, concepto que se basa, esencialmente, en las concepciones de los pueblos andinos y amazónicos. Se trata de demostrar como, por medios que se inician en el proceso de colonización de América, la historia que informa el campo de las Relaciones Internacionales es centrada en la visión europea-occidental, ocultando partes relevantes del pasado y, con eso, otras visiones de mundo, motivos por los cuales se termina la discusión con el abordaje del Buen Vivir como alternativa.

\section{PALABRAS CLAVE}

Relaciones Internacionales. Poscolonialismo. Pensamiento decolonial. Eurocentrismo. Buen Vivir. 


\section{INTRODUÇ̃̃̃O}

O campo das Relações Internacionais, desde seu surgimento até os tempos recentes, mantém o predomínio dos construtos teóricos originados, principalmente, nos grandes centros de pesquisa da Europa Ocidental e Estados Unidos. De tal maneira, como se buscará discutir, a produção de conhecimento, o qual, por conseguinte, serve como suporte à própria política, trabalha de maneira cíclica, no sentido de se autoafirmar, mantendo excluídos fatores históricos fundamentais que serviram à sua construção, bem como outras visões de mundo diferentes da ocidental e de origem europeia acerca das Relações Internacionais.

Nesse sentido, a colonização da América, iniciada no final do século XV e seus desdobramentos são tidos, como será visto, como elementos fundamentais para se entender a realidade atual, tanto dos países colonizadores como daqueles que foram colonizados. Assim, por meio de uma revisão bibliográfica com vistas a discutir o eurocentrismo nas teorias político-sociais, propõe-se um debate enfocado nas Relações Internacionais, apresentando-se o pensamento pós-colonial surgido na área, promovendo um debate com a corrente decolonial latino-americana e as concepções que formam a ideia de Bem Viver como uma alternativa de pensamento.

Na primeira seção, traz-se o debate realizado pelo viés pós-colonialista nas Relações Internacionais. Esse pensamento entra na discussão, sobretudo, na virada dos anos 1980/1990, criticando os pressupostos que fundamentam a disciplina e as teorias chamadas mainstream. De tal maneira, como se verá com os autores analisados, questões raciais, de gênero, de colonialismo etc., sendo componentes históricos fundamentais para a construção e manutenção de elementos centrais da disciplina, a qual se baseia no modelo europeu ocidental de organização social, econômica e política, são mantidos à margem da discussão, baseando-se, apenas, na história da própria Europa.

Feita a crítica com maior enfoque no próprio campo das Relações Internacionais (RI), a seção seguinte se dedica a trazer a América Latina à conversa, por meio da discussão a respeito do pensamento decolonial. Tal vertente do pensamento social trata de demonstrar como a colonização, baseando-se, em grande medida, no argumento da superioridade racial, tendo a colonização da América como ponto de partida, alcançou expandir seu modelo de civilização para a quase totalidade do globo. Os pensadores, portanto, advogam pela importância da descolonização do pensamento (MIGNOLO, 2008), a fim de se abrir espaço a outras visões de mundo e conhecimentos silenciados pela colonialidade, sustentada em um conhecimento a-histórico.

Finalmente, após se discutir o pós-colonialismo nas Relações Internacionais e como o pensamento decolonial se articula em sua crítica a ele, o último elemento da discussão trazido é o da alternativa, por assim dizer, que vem surgindo na América Latina aos cânones ocidentais predominantes.

O Bem Viver, formado, essencialmente, por concepções provenientes de cosmovisões de povos tradicionais das regiões andina e amazônica tem encontrado cada vez mais espaço, do qual são maiores expressões as mudanças ocorridas na Bolívia e no Equador. Com suas ideais, como se verá, o que se busca é a retomada de conhecimentos e formas de organização social, econômica e política, silenciadas pelo colonialismo europeu, as quais dotadas de maior legitimidade para a compreensão de realidades diversas. 


\section{PÓS-COLONIALISMO NAS RELAÇÕES INTERNACIONAIS: MOTIVAÇÕES PARA A CRÍTICA}

A teoria pós-colonial ou o pós-colonialismo no campo das RI passou a figurar nos debates, principalmente, no final dos anos 1980 e início dos 1990 do século passado. Situado entre as teorias críticas, o pós-colonialismo trata de tecer contrapontos às teorias ditas mainstream das Relações Internacionais, em função de que seus pressupostos foram criados e seguem sendo sustentados em pontos de vista restritos, isto é, de potências da Europa Ocidental, em primeiro momento, e, após, também dos Estados Unidos da América (EUA) como principal potência mundial a partir da metade do século XX.

De tal maneira, conforme se verá de forma mais esmiuçada, a crítica pós-colonial, propondo releituras históricas, trata de demonstrar que a visão ocidental e eurocêntrica deixa de fora questões fundamentais para se entender a política internacional. Em função de que seus principais autores se encontram e produzem a partir, especialmente, de grandes centros da Europa e dos EUA, seus trabalhos, naturalmente, reforçam sua própria perspectiva, deixando de fora assuntos imprescindíveis como etnia, raça, gênero, colonialismo, enfim, problemas que implicam e implicaram na política internacional, mas que são mantidos em segundo plano.

A primazia do eurocentrismo nas RI, como sustentam vários autores dentre os quais alguns que serão aqui mencionados, tem suas raízes no final do século XV, quando o colonizador europeu inicia a colonização do que viria a se chamar de América. A partir de então, ao longo do século seguinte, com a subjugação dos povos nativos locais e a desapropriação massiva e forçada de recursos que possibilitaram a impulsão do capitalismo em benefício dos colonizadores, começa a ser forjada a identidade do europeu como modelo superior de organização econômica, política e social (TAYLOR, 2012).

Nesse sentido é que são possibilitados os pressupostos que hoje são centrais às principais teorias do campo e que guiam o próprio funcionamento da política internacional, com a ideia de Estado-nação como a forma de organização política natural, a soberania como um de seus principais elementos, o capitalismo como modelo econômico, o racionalismo em vez de uma dita crença em mitos, entre outros. Conforme as palavras de Krishna sobre o pós-colonialismo, em ensaio próprio sobre o tema:

Uma perspectiva pós-colonial, para este ensaio, implica em uma sensibilidade para as relações hierárquicas entre raças, gêneros e classes; para a etnocentricidade de uma disciplina, que, por definição e nomenclatura (relações internacionais), deveria enfatizar o caráter histórico e inter-relacionado dos desenvolvimentos ao longo dos últimos séculos; que controla os discursos dominantes dos nossos tempos; e para o papel da teoria crítica internacional nos intermináveis jogos de poder (KRISHNA, 1993, p. 390, tradução nossa³).

Em vez de uma disciplina verdadeiramente histórica, na qual fossem estudadas as diversas dinâmicas que contribuíram para a composição atual do sistema internacional, os marcos estudados em

3 Texto original: [...] a postcolonial perspective for this essay will entail a sensitivity to the hierarchical relations between races, genders, and classes; the ethnocentricity of a discipline that, by definition and nomenclature (international relations), should emphasize the historical and interrelated character of developments over the last few centuries; who controls the dominant discourses of our times; and the role of critical international theory in the endless plays of power. 
Relações Internacionais se referem àqueles que remontam à história europeia - deixando de lado as partes da dominação e escravização de outros povos. Ademais da conquista das Américas, a escravização e tráfico de pessoas do continente africano, o genocídio de povos indígenas na própria América, a exploração, a opressão, são todos elementos que, de alguma maneira, são ocultados (ou, pelo menos, mantidos fora de debate) na história contada pelas Relações Internacionais.

Ao indagar se "É possível que, realmente, nenhum desses processos tenha, significativamente, moldado o desenvolvimento da ordem internacional (...)?” (SETH, 2011, p. 173, tradução nossa4), Sanjay Seth menciona que, assim como o período do desenvolvimento do capitalismo coincidiu com a conquista colonial, ele se deu com outros eventos e processos privilegiados no estudo convencional das Relações Internacionais ${ }^{5}$. De tal maneira, além da violência física, ocorre também a de caráter epistemológico, onde outras 'histórias' são ocultadas pela versão eurocentrada dos fatos.

A partir desse ocultamento - afora aquele que ocorre sobre as distintas manifestações culturais, suas formas de relações político-sociais e econômicas -, são, igualmente, obscurecidas as lutas dos diversos povos contra o conquistador ou subjugador. Para tanto, elaboram-se os argumentos de progresso linear (primitivo/moderno), de racionalidade, de modernidade, de progresso etc., reforçados por teorizações que sustentam tais afirmações e que confabulam com a história contada pelo Ocidente (DARBY, 2004).

Percebe-se, portanto, que os elementos sobre os quais a disciplina das Relações Internacionais assenta suas bases favorecem a manutenção de um caráter excludente nas discussões que ocorrem dentro do campo. Em função do predomínio ocidental na produção de conhecimento, barreiras são erigidas para a aceitação de debates levantados em determinadas localidades "não centrais", de forma que o conteúdo considerado como legítimo para informar o campo das RI mantém visões de mundo, concepções sociais, culturais e políticas que não considera como válidas ou relevantes fora de discussão, ocultadas.

Acerca disso, de acordo com Phillip Darby, "a construção do discurso político contemporâneo do ocidente marginaliza a luta dos povos não-europeus por justiça econômica e igualdade racial, assim como desconta sua experiência histórica de expropriação" (DARBY, 2004, p. 3, tradução nossa6).

Indo mais longe, Sankaran Krishna (2001) comenta que tais buscas por justiça e compensação pelo passado de violência são tratados sob os discursos que chama de "salvação adiada"?. Segundo ele, esses discursos aparecem de diversas formas nas RI, como a ideia da Paz Perpétua de Kant, a esperança de uma comunidade internacional do seio das Nações Unidas, o argumento da modernização capitalista em Rostow, entre outros que cita, todos tendo como característica uma "salvação" futura para a violência e desigualdade em correntes (KRISHNA, 2001).

4 Texto original: Could it really be that none of these processes significantly shaped the development of the international order [...]? 5 A título de complementação, segue o que completa Seth: [...] the peace of Augsburg and the settlement of Westphalia roughly coincide with the subjugation and settlement of the Americas, the rise of the slave trade, the founding of the British East India Company and the Dutch East India Company, Macartney's mission to the Middle Kingdom, and so on.

6 Texto original: the construction of the political in contemporary Western discourse marginalises the struggle of non-European peoples for economic justice and racial equality and discounts their historical experience of dispossession. 7 Versão do autor para a expressão “deferred redemption”, na língua inglesa, utilizada por Krishna. 
Pôr em debate a questão da soberania auxilia-nos a direcionar a discussão para o tema dos povos indígenas no âmbito das RI, tema aqui em conversa. Krishna (2001) comenta que, na disciplina, "Cem Anos de Paz" é a caracterização dominante para referir-se ao mundo no século XIX. No entanto, segue ele, o período abrangido entre 1815 e 1914 não foi de nada pacífico, tendo sido permeado por inúmeros conflitos ao redor do globo, dentre os quais cita as Guerras do Ópio na China (1839-1842), a Guerra da Crimeia (1854-1856), a destruição da resistência dos Maori na Nova Zelândia (1871), a conquista do Egito (1882), entre tantos outros.

O silêncio mantido a respeito desses conflitos se deve a um dos pilares do Estado-nação, construído na narrativa ocidental das Relações Internacionais: a soberania.

Pensando acerca do que permite que esses numerosos e violentos encontros entre diferentes povos sejam mantidos fora da história das relações internacionais, se torna óbvio que um certo princípio de abstração está em questão, centrado no conceito de "soberania". (KRISHNA, 2001, p. 405, tradução nossa8).

É dizer, apesar dos inúmeros conflitos, apenas aqueles entre Estados soberanos entraram no discurso, restando de fora os demais encontros que envolvem as diversas formas de "quase-Estados". Mais uma vez, percebe-se o ocultamento de parte da história, dando ênfase apenas à parte que favorece ou corrobora os argumentos que constroem a narrativa apresentada nas RI.

Ao tratar da questão indígena e do "internacional", especificamente no que toca à soberania, Karena Shaw (2002) comenta que luta dos povos indígenas não é, necessariamente, a luta por voltar a viver como no passado, com uma forma de soberania anterior à colonização; tampouco para ser totalmente integrados à forma de organização do colonizador. 0 que buscam é que lhes sejam possibilitadas autoridades legitimas, isto é, soberanias, dentro e por meio das condições espaço-temporais da soberania moderna, como uma espécie de soberania dentro da soberania; "eles visam criar soberanias pós-coloniais; eles visam criar soberanias 'locais' ecológica e socialmente viáveis dentro e através dos processos de 'globalização', e assim por diante” (SHAW, 2002, p. 58, tradução nossa99).

Em seu trabalho, a autora discute a constituição de autoridades nas e por meio das instituições políticas, incluindo a academia, bem como de que maneira isso se relaciona e quais as possibilidades suscita para os povos indígenas. Conforme ela, a história dos povos indígenas é uma história de resistência persistente contra os projetos e conceitos de modernização, progresso e desenvolvimento, os quais, aparentemente, não lhes alcançam, visto que, diferente das vítimas mais recentes da colonização, aquela que teve marcha nos séculos XIX e XX, esses povos ainda não passaram pelo processo de descolonização (SHAW, 2002).

Portanto, como se tratou de mostrar até aqui, o estudo das Relações Internacionais, considerada a sua concentração na produção de conhecimento pelos países ocidentais - principalmente aqueles

8 Texto original: In thinking of what it is that allows these numerous and violent encounters between diferente peoples to fall out of the history of international relations, it becomes obvious that a certain principle of abstraction is at work here, centering on the concept on the concept of "sovereignty".

9 Texto Original: They seek to create post-colonial sovereignties within sovereignties; they seek to create economically and ecologically viable 'local' sovereignties within and through processes of 'globalisation', and soo n. 
de língua inglesa -, reproduz uma lógica excludente com relação a outras concepções de organização política, social e, consequentemente, econômica. De tal maneira, além dessas inúmeras formas de pensar que foram ocultadas, o mainstream das RI mantém às margens das discussões os teóricos de diversas partes do globo. Por conseguinte, segue-se o diálogo, trazendo o debate acerca da colonialidade empreendido por teóricos latino-americanos.

\section{AMÉRICA LATINA E O PENSAMENTO DECOLONIAL}

De maneira semelhante ao ocorrido na disciplina de Relações Internacionais quanto ao pós-colonialismo, a partir da década de 1990, começam a se destacar na teoria política e social os estudos deocoloniais na América Latina. Os anseios de seus pensadores, outra vez assemelhando-se ao que ocorreu nas RI, são o de promover a crítica ao pensamento predominante no campo social e político, visto que sua produção emerge, principalmente, de grandes centros de pesquisa que teorizam "desde fora”, e, consequentemente, a partir de percepções diversas das vivenciadas pelos próprios latino-americanos.

Importante mencionar que o pensamento latino-americano não surge do nada. A abordagem decolonial busca inspiração na linha de pensamento propriamente chamada de pós-colonial, a qual se inseriu no âmbito das Relações Internacionais. No entanto, conforme se abordará nesse momento, as principais distinções ensejadas no estudo decolonial se referem, em específico, ao esforço de chamar a atenção para a experiência colonial latino-americana e as sequelas que até hoje são percebidas nas relações sócio-política dos países da região.

De acordo com o que comenta Luciana Ballestrin (2013), o debate a respeito da relação antagônica entre o colonizador e colonizado começa antes mesmo de ser consolidado o chamado pensamento pós-colonial. Segundo a autora, o antagonismo dessa relação, o qual impede a constituição plena de um ou outro lado, isto é, um existindo em função do outro, foi trazido, pela primeira vez, por Franz Fanon. Ao lado dele, a autora coloca Aimé Césaire, Albert Memmi e Edward Said ${ }^{10}$ como "os porta-vozes que intercederam pelo colonizado quando este não tinha voz” (BALLESTRIN, 2013, p. 92), no movimento que se iniciou em meados do século passado.

Ao redor da década de 1970, os chamados "grupos de estudos subalternos" começam a surgir no sul asiático e, na década posterior, tomam lugar na Índia, em especial representado por autores como Partha Chatterjee, Dipesh Chakrabarty e Gayatri Chakrabarty Spivak.

A América Latina entra na discussão somente a partir da década de 1990, com o Grupo Latino-Americano de Estudos Subalternos, o qual passou a sofrer fortes críticas de um de seus membros, Walter Mignolo, o qual, segundo Ballestrin, “denuncia o 'imperialismo' dos estudos culturais, pós-coloniais e subalternos que não realizaram uma ruptura adequada com autores eurocêntricos” (BAL-

10 Conforme informações trazidas por Ballestrin (2013): Franz Fanon (1925-1961) era um psicanalista, negro, nascido na Martinica e revolucionário do processo de libertação nacional da Argélia; Aimé Césaire (1913-2008) era poeta, negro, também nascido na Martinica; Albert Memmi (1920-) é um escritor e professor, nascido na Tunísia, de origem judaica; e Edward Said (1935-2003), era um crítico literário de origem palestina, intelectual e militante da causa. 
LESTRIN, 2013, p. 95). Ocorre, então, uma dissidência, que dá origem ao Grupo Modernidade/Colonialidade, que inaugura o chamado giro decolonial.

0 pensamento decolonial, em tom semelhante ao que se abordou acerca do pós-colonialismo nas Relações Internacionais, busca dar voz a outras visões e concepções que não aquelas produzidas pelo discurso ocidental. Sendo a América Latina o local a partir de onde, no final do século XV, se inaugura um novo modelo de dominação e colonização, essa corrente de pensamento vem a dialogar em torno dos desdobramentos de tal modelo, de como desse acontecimento decorreu a hierarquização racial nas relações sociais e, desde aí, a construção do discurso ocidental como superior aos demais povos.

A respeito disso, em nota explicativa, Walter Mignolo, um dos nomes relevantes do pensamento decolonial e, portanto, críticos do eurocentrismo, comenta que o objetivo é a "descolonização do conhecimento científico e [a] liberação de formas de conhecer silenciadas e marginalizadas pela retórica moderno-ocidental (e epistêmico-imperial) da 'ciência”' (MIGNOLO, 2008, p. 247, tradução nossa $\left.{ }^{11}\right)$. Conforme ele, "há uma tendência geral a aceitar-se o pensamento construído a partir da história e experiência europeia como des-localizado" (MIGNOLO, 2008, p. 258, tradução nossa ${ }^{12}$ ).

Ou seja, a pluralidade de trajetórias históricas percorridas pelos diferentes povos e nações é, reincidentemente, tratada de ser mantida ocultada debaixo de uma universalização de conceitos e concepções guiados pela experiência histórica da Europa. Assim, a "retórica moderno-ocidental”, como alude Mignolo, se sustenta sobre esquecimento de violências históricas, bem como se furta de incluir em seus debates a questão da colonialidade ainda presente na América Latina e outras regiões antes colonizadas.

Enrique Dussel (2005), revisando trajetórias históricas, visou demonstrar como se formou aquilo que hoje conhecemos por Europa. Além do mais, o autor tratou de ressaltar, principalmente, a manipulação conceitual que, durante o século XVIII, foi reforçada para que a "Europa moderna" tivesse como origem o caminho unilinear Grécia-Roma-Europa. Dentre os vários esquemas que apresenta, o que Dussel trata de elucidar são os diversos contatos e caminhos históricos que possibilitaram a formação da Europa atual, chamando a atenção para o fato de que não há uma única história mundial.

Ao lado da ideia de "Europa moderna" emergiu a própria ideia de "moderno", isto é, aquilo que se opõe ao atraso, que representa maturidade. Dussel traz duas visões que representam a ideia de moderno ou modernidade. A primeira delas se refere a uma "saída da imaturidade por um esforço da razão como processo crítico, que proporciona à humanidade um novo desenvolvimento do ser humano" (DUSSEL, 2005, p. 27). Esse processo de desenvolvimento teria se iniciado no século XV, mas ocorrido, em essência, no século XVIII, sendo aceitos e reproduzidos (autor dá como exemplo os escritos de Hegel e Habermas) pela tradição europeia atual.

A segunda etapa da modernização tem início com a chegada europeia ao continente americano, em 1492. A partir de então, passa a ser construída a ideia da Europa como centro da história mundial,

11 Texto original: de-colonización del conocimiento científico y liberación de formas de conocer silenciadas y marginalizadas por la retórica moderno-occidental (y epistémico-imperial) de la “ciencia”.

12 Texto original: hay una tendencia general a aceptar el pensamiento construido a partir de la historia y experiencia europea como des-localizado. 
diferente das várias histórias coexistentes do período anterior, com todas as demais culturas, passando a ser sua periferia. Nas palavras de Dussel:

Ou seja, empiricamente nunca houve História Mundial até 1492 (como data de início da operação do "Sistema-mundo). Antes dessa data, os impérios ou sistemas culturais coexistiam entre si. Apenas com a expansão portuguesa desde o século XV, que atinge o extremo oriente no século XVI, e com o descobrimento da América hispânica, todo o planeta se torna o "lugar" de "uma só" História Mundial (Magalhães-Elcano realiza a circunavegação da Terra em 1521). (DUSSEL, 2005, p. 27).

Com a colonização da América, portanto, é que restou possibilitada a ascensão da Europa como centro do mundo. Por conseguinte, uma série de categorizações passaria a ser criada para sustentar essa supremacia. A primeira delas, a "categorização" dos humanos com a criação da ideia de raça. É dizer, desde esse momento, o conquistador passa a se considerar como uma raça naturalmente superior, distinta biologicamente do conquistado, o qual passa a tratar como inferior.

É a partir da empreitada colonial que passa a se constituir a ideia da superioridade racial. Conforme afirma Aníbal Quijano (2005), não há conhecimento do uso da ideia de raça em tal sentido em momento algum anterior à conquista da América; as relações sociais que aí se estabelecem servem para expandir o modelo europeu de dominação para o restante do globo.

Assim, sendo o branco europeu a raça superior, suas instituições, por conseguinte, também o seriam com relação às dos demais povos. Isso serviria, ademais, para justificar (ainda que para si próprios) as conquistas sobre povos ditos inferiores.

Com essas relações de dominação, o que se via era o paulatino apagamento de diversas formas de organização social, política e econômica, as quais eram reprimidas e somente sendo aproveitadas na medida em que eram úteis à empreitada colonial. 0 etnocentrismo europeu, baseado na classificação de raças da qual eram os superiores, elevou a Europa ao status de moderno, avançado, em contraste com todos os demais povos, raças inferiores, situadas no passado.

De acordo com essa perspectiva, a modernidade e a racionalidade foram imaginadas como experiências e produtos exclusivamente europeus. Desse ponto de vista, as relações intersubjetivas e culturais entre a Europa, ou, melhor dizendo, a Europa Ocidental, e o restante do mundo, foram codificadas num jogo inteiro de novas categorias: Oriente-Ocidente, primitivo-civilizado, mágico/mítico-científico, irracional-racional, tradicional-moderno. Em suma, Europa e não-Europa. (QUIJANO, 2005, p. 122).

Esse caráter binário, baseado em uma história linear de tempo, produzido a partir da elevação da Europa como modelo de uma ideia de moderno vem sendo confrontado pelo pensamento decolonial. Essa, entretanto, não é uma tarefa simples, dada sua impregnação no tecido social. A colonialidade, nesse sentido, se expressa nos diversos âmbitos das relações sociais, mantendo impedida a expressão da pluralidade, controlando o modelo de economia, de autoridade, o conhecimento etc. Conforme 
Ballestrin, "a colonialidade é o lado obscuro e necessário da modernidade" (BALLESTRIN, 2003, p. $\left.100^{13}\right)$; a mentalidade colonial é o que sustenta a ideia de modernidade.

A respeito disso, apesar de não ser um autor latino-americano, merece menção o que escreveu Boaventura de Sousa Santos (2010) ao comentar acerca da necessidade da superação das chamadas "teorias críticas", visto que mantêm o caráter eurocêntrico. Diz ele que novos conceitos necessitam ser incluídos nas ciências sociais para dar conta de todos os movimentos de luta que têm surgido na América Latina nos últimos trinta anos, protagonizados por "indígenas, campesinos, mulheres afrodescendentes, piqueteiros, desempregados” (SANTOS, 2010, p. 17, tradução nossa ${ }^{14}$ ). Esses atores, conforme Sousa Santos, não se expressam na língua em que se redigiu a teoria crítica, mas em suas línguas nacionais, dotados de seus próprios significados.

Para pensarmos esses novos movimentos, após terem sido analisadas, brevemente, as concepções que baseiam o pós-colonialismo no seio das Relações Internacionais, assim como o pensamento decolonial entre os autores latino-americanos, o trecho final traz a abordagem a respeito do Bem Viver. Esse ideário vem tomando parte na América Latina, trazendo alternativas aos modelos ocidentais ainda que sem excluí-los - de economia, política e sociedade, tomando como base concepções dos povos que aqui habitam e habitaram desde antes da dominação europeia.

\section{BEM VIVER COMO ALTERNATIVA}

Importante salientar desde o início que, assim como feito como nos trechos anteriores a respeito do pós-colonialismo e do pensamento decolonial, a intenção aqui não é realizar uma análise aprofundada acerca da gênese do conceito de Bem Viver. O que se pretende é discorrer a respeito de alguns de seus principais elementos e ideias, visando a proposição de um diálogo com as partes anteriores e demonstrando como esse conceito se insere na contraposição ao pensamento ocidental predominante. Dá-se início, para tanto, por algumas notas acerca da origem da ideia de Bem Viver.

Esse conceito vem sendo retomado na América Latina nas últimas décadas como uma alternativa ao modelo vigente de organização social e de desenvolvimento. Suas ideias visam buscar concepções e conhecimentos tradicionais dos povos indígenas andinos e amazônicos, os quais permaneceram silenciados por muito tempo em função do processo de colonização e, posteriormente, pela hegemonia do modelo ocidental de desenvolvimento. Suas propostas, ademais, acabaram por estar expressas nas novas constituições de Equador, em 2008, e Bolívia, em 2009 (ACOSTA, 2015).

Não se trata de um conceito com raiz única, algo que se pode denotar do mencionado acima, considerada a grande pluralidade de povos que habitaram e habitam as regiões amazônica e andina. Conforme Acosta (2014), no caso do Equador, Bem Viver ${ }^{15}$ é mencionado nos termos sumak kawsay, do idioma

13 Em seu texto, autora faz referência a Mignolo (2003).

14 Texto original: indígenas, campesinos, mujeres, afrodescendientes, piqueteros, desempleados.

15 Salienta-se o fato de que no original, em espanhol, o Bem Viver é tratado, segundo Acosta (2014), como Buen Vivir no Equador e como Vivir Bien na Bolívia. 
kichua; no da Bolívia, são utilizados o suma qamaña, do aymara, e sumak kawsay, do quéchua ${ }^{16}$.

$O$ sentido do termo tem a forma de um conceito holístico, devendo ser visto como plural, como se existisse mais de um Bem Viver, fruto da filosofia indígena de buscar uma vida plena, em harmonia com seus congêneres e com a natureza, respeitando-se a vida e a convivência (ACOSTA, 2014).

A retomada de tais concepções tradicionais, provenientes de povos que há muito habitam o território que se passou a chamar de América não significa uma regressão ao passado ou a tempos e práticas primitivas, em sentido pejorativo (FÉLIZ, 2015). Diferente disso, o Bem Viver propõe uma alternativa à lógica de desenvolvimento ocidental que vem sobrecarregando o meio ambiente com a extração massiva daquilo que considera como "recursos" naturais e que vem vitimando aqueles que estão em seu caminho. A proposta, de acordo com Féliz, é de uma ideia de "viver bem como paradigma", remetendo à “preeminência do valor de uso sobre o valor de troca” (FÉLIZ, 2015, p. 36, tradução nossa ${ }^{17 ; 18}$ ).

Ao lado da busca por recuperar os saberes tradicionais, com o conceito de Bem Viver a proposta é a de que sejam construídas formas de produção que superem os paradigmas atuais. Que o ser humano volte a se ver como parte da natureza, deixando de mercantilizá-la e de vê-la como um recurso inesgotável para geração e acumulação de capital financeiro. Que se resgate, ademais, o sentido solidário e comunitário entre as pessoas, a fim de que as formas de produção obedeçam às necessidades vitais da sociedade, no lugar da devastação social e ambiental que se tem visto em diferentes locais (FÉLIZ, 2015; ACOSTA, 2014; 2015).

Essas propostas, sem embargo, não são simples de serem cumpridas, nem é essa a ideia. Como se viu anteriormente, o robustecimento do conceito ocidental de modernidade, que carrega consigo, dentre outros, o modelo capitalista de desenvolvimento, ocorreu ao largo do desenrolar histórico e ganhou alcance amplo durante o século XX.

Na América Latina, bem como em outras partes do globo, culturas e saberes tradicionais são postos de lado e, além do mais, seus povos são tratados com preconceito, debilitando o peso da luta de suas demandas, o que se reflete nas políticas governamentais de desenvolvimento. Propor que se mude essa situação, por conseguinte, requer a consciência de que seja algo gradual e que se estenda ao longo do tempo.

Como menciona Acosta (2014, p. 25, tradução nossa ${ }^{19}$ ), de maneira geral, “o desenvolvimento, enquanto proposta global e unificadora, desconhece de uma maneira violenta os sonhos e lutas dos povos “subdesenvolvidos”. Desde a colonização até o presente, a América Latina vem sendo vista como um depósito de recursos naturais e fonte de crescimento econômico. Seus diferentes governos e líderes são permeados pela mesma matriz histórica e cultural, o que torna difícil a alteração dessa lógica, sendo o 'lugar da natureza’ uma das tensões fortes que cercam o Bem Viver (GUDYNAS, 2011).

16 Afora estes, o autor também menciona que há concepções semelhantes para outros povos, como para os mapuche no Chile, os guaranis na Bolívia e no Paraguai (lembrando que são povos também habitantes do Brasil), os kuna no Panamá, os achuar na Amazônia equatoriana e os maias na Guatemala e no México.

17 Texto original: vivir bien como paradigma.

18 Texto original: preeminencia del valor de uso por sobre el valor de cambio.

$19 \mathrm{El}$ desarrollo, en tanto propuesta global y unificadora desconoce de una manera violenta los sueños y luchas de los pueblos "subdesarrollados". 
O fator crucial da retomada do conceito de Bem Viver está em que reacende ideias existentes desde muito na periferia global, e, além do mais, na região onde o padrão de desenvolvimento, fruto da colonialidade ocidental eurocêntrica, começou a ganhar forma com a colonização da América Latina no final do século XV.

Dois de seus elementos fundacionais que buscam ser superados por meio da alternativa do Bem Viver são a ideia de racionalidade, no sentido separação do ser racional - humano - da natureza, e de superioridade racial como parte dessa natureza, o que foi utilizado como justificativa ou explicação para a exploração das supostas raças inferiores (QUIJANO, 2012).

Além disso, menciona-se a concepção de “Estado-nação", que veio a ter a democracia liberal como modelo ideal e a maneira como se sobrepôs a diferentes maneiras de organização social. Sua estrutura é pensada para controlar o trabalho, os recursos e autoridade, de forma a dispersar uma existência social diversa em uma totalidade tida como nação ou sociedade (QUIJANO, 2000).

No caso latino-americano, os indígenas, regra geral ${ }^{20}$, sendo uma ínfima parcela da população, têm pouquíssima influência nos interesses dessa nação. Como consequência, o colonialismo interno segue imperando, isto é, a concepção ocidental de desenvolvimento em favor do interesse nacional segue se sobrepondo, sem grandes alardes, aos dos povos indígenas.

Acosta (2015) aponta algumas formas a partir das quais se deve buscar, paulatinamente, essas mudanças em favor do Bem Viver e, por conseguinte, dos povos indígenas. Segundo ele, é necessário que se busque o fortalecimento das organizações políticas e econômicas desde baixo, ou seja, fruto de movimentos populares, como aquelas que surgem em bairros e comunidades rurais ou campesinas. Isso implica, conforme o autor, em "ir gestando, desde o local, espaços de poder real no campo político, econômico e cultural” (ACOSTA, 2015, p. 319, tradução nossa ${ }^{21}$ ).

Enfrentar a colonialidade que permeia os âmbitos da sociedade, significa, igualmente, "desandar um Estado autoritário, racista e burocratizado, pensado e constituído para a dominação, a fim de convertê-lo em um espaço de gestão social” (FÉLIZ, 2015, p. 44, tradução nossa22), sendo essa a maior dificuldade. Dificuldade esta que

[...] persiste nos empreendimentos extrativistas, apelando, por exemplo, a minimizar ou ignorar os impactos ambientais, subestimar os reclames de grupos locais ou movimentos indígenas, ou apelar à necessidade de sacrifícios locais em favor do bem-estar geral. (GUDYNAS, 2011, p. 238, tradução nossa23).

20 Diz-se regra geral em função dos mencionados exemplos de Bolívia e Equador, ainda que nesse último a população indígena seja de menor número.

21 Texto original: ir gestando, desde lo local, espacios de poder real en lo político, en lo económico y en lo cultural.

22 desandar un Estado autoritario, racista y burocratizado, pensado y construido para la dominación, para convertirlo en un espacio de gestión social

23 persiste en los emprendimientos extractivistas apelando, por ejemplo, a minimizar o ignorar los impactos ambientales, desestimar los reclamos de grupos locales o movimientos indígenas, o apelar a la necesidad de sacrificios locales a favor del bienestar general. 
De acordo com Gudynas (2011) e no mesmo tom em que se vem discutindo, é necessário que se supere a defesa do crescimento econômico infinito, de progresso como algo linear (velho/novo; tradicional/desenvolvido; primitivo/moderno), assim como a visão utilitarista sobre a natureza como sinônimo ou meio para o desenvolvimento. O Bem Viver como alternativa demanda que se supere a concepção de ter mais ou consumir mais para sermos felizes, o que, por conseguinte, implica em produzir mais e extrair mais a todo o custo, algo que está intrínseco na maneira de viver baseada na modernidade ocidental.

A própria vivência e sobrevivência desses povos milenares é exemplo de que se pode viver, contra todas as adversidades, em um modo diverso. Como mencionam todos os autores que se citou a respeito do Bem Viver, a ideia não é de um conceito pronto, que esteja posto como um modelo a ser aplicado. “A importância do paradigma do Bem Viver não está na realização imediata de uma ruptura, mas na retomada de um horizonte - um futuro com justiça e igualdade” (BONIN, 2015, p. 3). Séculos de resistência e, recentemente, de uma retomada de espaço das concepções indígenas mostram que esse novo paradigma pode, igualmente, ganhar maior observância.

Por fim, há que se ter em conta que isso "não surgirá da noite para o dia e menos ainda pelas mãos de caudilhos iluminados” (ACOSTA, 2015, p. 327, tradução nossa ${ }^{24}$ ), mas é uma proposta de revisão às formas de produção e de consciência que imperam atualmente. O Bem Viver propõe uma alternativa pluralista, que busque eliminar os resquícios do preconceito de raça e de gênero, que retome o ser humano com parte da natureza, que viva em harmonia como parte dela, que traga o diálogo entre saberes tradicionais e modernos, buscando sempre o bem coletivo e não o individual.

Como conclui Quijano (2012, p. 55, tradução nossa25), “a proposta de Bem Viver é, necessariamente, uma questão histórica aberta que requer ser continuamente indagada, debatida e praticada”.

\section{CONSIDERAÇÕES FINAIS}

Como visto até aqui, iniciou-se a discussão a partir do pensamento pós-colonial nas Relações Internacionais. Ao proceder dessa maneira, a intenção foi a de apresentar como se construiu a crítica aos elementos centrais que são sustentados pelas teorias mainstream do campo das RI. Conforme ressaltam os autores, os pressupostos teóricos que compõem essas teorias se sustentam em narrativas seletivas da história, as quais deixam de lado violências e lutas que desautorizariam, minimamente, seus argumentos.

Ao retomar a indagação de Seth (2011), é possível que o estabelecimento do processo colonizador da América esteja desvinculado, de fato, da subsequente ascensão europeia, no sentido de moldar a ordem internacional vindoura? Nesse ponto é que se une a crítica inicial àquela feita pelo pensamento decolonial.

A proposta, criticando esse caráter “a-histórico" que permeia as Relações Internacionais e as Ciências Sociais, que conta a história apenas pela visão do colonizador, é a de contrapor o binarismo

24 no surgirá de la noche a la mañana y menos aún de la mano de caudillos iluminados

25 la propuesta de Bien Vivir es, necesariamente, una cuestión histórica abierta / 6 que requiere ser continuamente indagada, debatida y practicada. 
inaugurado pelo europeu. Propõe, nas palavras de Quijano, combater as categorizações entre "primitivo-civilizado, mágico/mítico-científico, irracional-racional, tradicional-moderno. Em suma, Europa e não-Europa” (QUIJANO, 2005, p. 122).

Com a alternativa do Bem Viver, assim, encerra-se o debate iniciado entre as duas correntes. Ao serem apresentados seus principais elementos, buscou-se ressaltar a resistência, há mais de cinco séculos, desses conhecimentos tradicionais frente ao ocultamento promovido pelo pensamento eurocêntrico. Como os próprios teóricos mencionam, a retomada de espaço por essas culturas tradicionais não advoga por que se regrida, pejorativamente, ao passado, mas que seja proposto um horizonte de mudança, de um futuro mais justo para inúmeros povos que foram marginados (não esquecendo dos que foram dizimados) pela colonização europeia.

Daí a importância de que seja discutido no âmbito das Relações Internacionais o colonialismo, as questões de raça, de gênero, assim como seja abordada a história a partir da visão dos povos que foram - e, em certa medida, seguem - colonizados. De tal maneira, diferente de se aceitarem modelos "prontos" de organização social, política e econômica, enseja-se, tal como propõe o Bem Viver, a construção alternativa a partir do debate, da indagação constante e da vivência diária, abrindo-se espaço para outras visões e outras histórias.

\section{REFERÊNCIAS}

ACOSTA, Alberto. El buen vivir como alternativa al desarrollo. Algunas reflexiones económicas y no tan económicas. Política y Sociedad, v. 52, n. 2, p. 299-330, 2015.

ACOSTA, Alberto. El buen vivir, más allá del desarrollo. In: RAMOS, Gian Carlo. Buena Vida, Buen Vivir: imaginarios alternativos para el bien común de la humanidad. UNAM, 2014.

BALLESTRIN, Luciana. América Latina e o giro decolonial. Revista Brasileira de Ciência Política, Brasília, n. 11, p. 89-117, maio-ago. 2013.

BONIN, lara. X Encarte Pedagógico: O Bem Viver Indígena e o futura da humanidade. Jornal Porantim, n. 381, 2015.

DARBY, Phillip. Pursuing the Political: A Postcolonial Rethinking of Relations International. Millennium: Journal of International Studies, v. 33, n.1, p. 1-32, 2004.

DUSSEL, Enrique. Europa, modernidade e eurocentrismo. In: LANDER, Edgardo (Org.). A colonialidade do saber: eurocentrismo e ciências sociais. Perspectivas latino-americanas. Colección Sur Sur. Buenos Aires: CLACSO, 2005. 
FÉLIZ, Mariano. ¿Qué hacer... con el desarrollo? Neodesarrollismos, buenvivir y alternativas populares. Sociedad y Economía, n. 28, jun.-jul., p. 29-50, 2015.

GUDYNAS, Eduardo. Tensiones, contradicciones y oportunidades de la dimensión cultural del Buen Vivir. In: FARAH H, Simone; VASAPOLLO, Luciano (Org.). Vivir bien: ¿Paradigma no capitalista? La Paz: Plural editores, 2011.

KRISHNA, Sankaran. Race, Amnesia, and the Education of International Relations. Alternatives, v. 26, p. 401-424, 2001.

KRISHNA, Sankaran. The Importance of Being Ironic: A Postcolonial View on Critical International Relations Theory. Alternatives: Global, Local, Political, v. 18, n. 3, p.385-417, 1993.

MIGNOLO, Walter. Historias locales/disenos globales: colonialidad, conocimientos subalternos y pensamiento fronterizo. Madrid: Akal, 2003.

MIGNOLO, Walter. La opción de-colonial: desprendimiento y apertura. Un manifiesto y un caso. Tabula Rasa, Bogotá, n. 8, p. 243-281, jan.-jun., 2008

QUIJANO, Aníbal. “Bien vivir”: entre el “desarrollo” y la des/colonialidad del poder. Viento Sur, n. 122, p. 36-56, 2012.

QUIJANO, Aníbal. Colonialidade do poder, eurocentrismo e América Latina. In: LANDER, Edgardo (Org.). A colonialidade do saber: eurocentrismo e ciências sociais. Perspectivas latino-americanas. Colección Sur Sur. Buenos Aires: CLACSO, 2005.

SANTOS, Boaventura de Sousa. Descolonizar el saber, reinventar el poder. Montevidéu: Ediciones Trilce, 2010.

SETH, Sanjay. Postcolonial Theory and the Critique of International Relations. Millennium: Journal of International Studies, v. 40, n. 1, p. 167-183, 2011.

SHAW, Karena. Indigeneity and the international. Millennium: Journal of International Studies, v. 31, n. 1, p. 55-81, 2002.

TAYLOR, Lucy. Decolonizing International Relations: Perspectives from Latin America. International Studies Review, v. 14, p. 386-400, 2012. 

Pelotas (2013) e em Relações Internacionais pela Universidade Federal de Pelotas (2016); Mestrando em Relações Internacionais pela Pontifícia Universidade Católica de Minas Gerais, Programa de Pós-Graduação em Relações Internacionais. E-mail: leonardoamadruga@gmail.com

\section{(2) (1) (-)}

Este artigo é licenciado na modalidade acesso abertosob a Atribuição-Compartilhalgual CC BY-SA

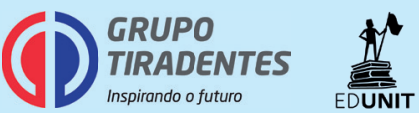

